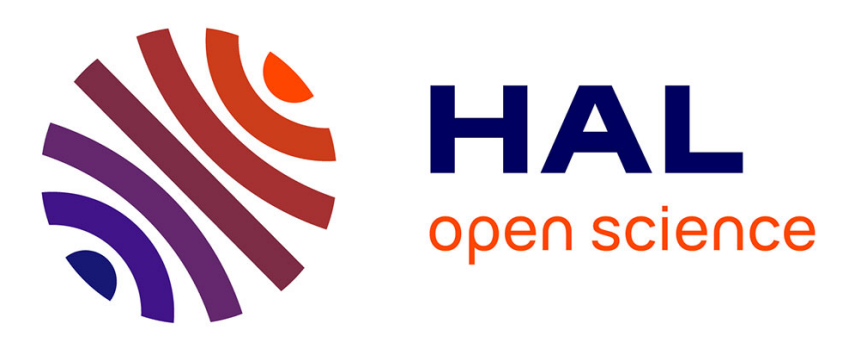

\title{
Magnetic control of flame stability: Application to oxygen-enriched and carbon dioxide-diluted sooting flames
}

Agnes Jocher, Jérôme Bonnety, Thomas Gomez, Heinz Pitsch, Guillaume

Legros

\section{To cite this version:}

Agnes Jocher, Jérôme Bonnety, Thomas Gomez, Heinz Pitsch, Guillaume Legros. Magnetic control of flame stability: Application to oxygen-enriched and carbon dioxide-diluted sooting flames. Proceedings of the Combustion Institute, 2019, 37 (4), pp.5637-5644. hal-02042962

\section{HAL Id: hal-02042962 \\ https://hal.sorbonne-universite.fr/hal-02042962}

Submitted on 21 Oct 2021

HAL is a multi-disciplinary open access archive for the deposit and dissemination of scientific research documents, whether they are published or not. The documents may come from teaching and research institutions in France or abroad, or from public or private research centers.
L'archive ouverte pluridisciplinaire HAL, est destinée au dépôt et à la diffusion de documents scientifiques de niveau recherche, publiés ou non, émanant des établissements d'enseignement et de recherche français ou étrangers, des laboratoires publics ou privés.

\section{(ㄷ)(1) $\$$}

Distributed under a Creative Commons Attribution - NonCommercial| 4.0 International 


\title{
Magnetic control of flame stability: application to oxygen-enriched and carbon dioxide-diluted sooting flames
}

\author{
Agnes Jocher ${ }^{1,2}$, Jérôme Bonnety ${ }^{2}$, Thomas Gomez ${ }^{3}$, Heinz Pitsch ${ }^{1}$, Guillaume Legros² \\ ${ }^{1}$ RWTH Aachen University, Institute for Combustion Technology, 52056 Aachen, Germany \\ 2 Sorbonne Universités, UPMC Univ Paris 06, CNRS UMR 7190, Institut Jean le Rond d'Alembert, 75005 Paris, \\ France \\ ${ }^{3}$ Université de Lille 1, 59655 Villeneuve d'Ascq, France \\ Corresponding author: Agnes Jocher \\ RWTH Aachen University, Institute for Combustion Technology, 52056 Aachen, Germany \\ Phone: +0033 (0)1308548 84 \\ Email address: ajocher@itv.rwth-aachen.de \\ Preferred colloquium topics: OTHER CONCEPTS \\ Alternative colloquia: LAMINAR FLAMES \\ Estimate of total length: 5937 \\ Method of determination: Method 2, LaTeX users, complete two-column formatted version \\ 6 pages $\times 900$ words/page $=5400$ \\ $221 \mathrm{~mm} \times 2.2$ words $/ \mathrm{mm}=486$ \\ $23 \mathrm{~mm} \times 2.2$ words $/ \mathrm{mm}=51$
}




\title{
Magnetic control of flame stability: application to oxygen-enriched and carbon dioxide-diluted sooting flames
}

\author{
Agnes Jocher ${ }^{\mathrm{a}, \mathrm{b}, *}$, Jérôme Bonnety ${ }^{\mathrm{b}}$, Thomas Gomez ${ }^{\mathrm{c}}$, Heinz Pitsch ${ }^{\mathrm{a}}$, Guillaume Legros ${ }^{\mathrm{b}}$ \\ ${ }^{a}$ RWTH Aachen University, Institute for Combustion Technology, 52056 Aachen, Germany \\ ${ }^{b}$ Sorbonne Universités, UPMC Univ Paris 06, CNRS UMR 7190, Institut Jean le Rond d'Alembert, 75005 Paris, France \\ ${ }^{c}$ Université de Lille 1, 59655 Villeneuve d'Ascq, France
}

\begin{abstract}
The present study explores possible stabilization mechanisms in flickering, sooting, ethylene flames burning in varying density coflow and exposed to different levels of an upward gradient of the square of the magnetic flux density $\left(\nabla\left(\mathbf{B}^{2}\right)\right)$. In normal gravity, flame flickering defines a natural large scale and low frequency flame oscillation that is induced by a so called modified Kelvin-Helmholtz type instability. To assess the potential of the magnetically induced stabilization process, a range of coflow mixtures with varying $\mathrm{N}_{2}, \mathrm{O}_{2}$, and $\mathrm{CO}_{2}$ contents in volume is studied. As a result, a domain of controllable flame stability is identified. Its extension depends on the maximum magnitude of $\nabla\left(\mathbf{B}^{2}\right)$, i.e. $18.2 \mathrm{~T}^{2} / \mathrm{m}$ for the present experimental setup. Spectral emission rate, spectral absorption coefficient, soot volume fraction, and soot temperature fields are measured in the flame by the Modulated Absorption/Emission technique (MAE). In agreement with former studies, the soot content is shown to play a key role in the stabilization process. Due to the magnetic force that is mainly acting on paramagnetic oxygen molecules, opposing gravity, and generated by $\nabla\left(\mathbf{B}^{2}\right)$, the residence time of soot particles in the flame presumably increases with $\nabla\left(\mathbf{B}^{2}\right)$. With growing soot volume fraction, radiative heat losses are enhanced leading to flame cooling. Therefore, flames exposed to the magnetic field exhibit both lower density gradients through the flame sheet and a weaker field of buoyant acceleration in the hot exhaust gas stream. Both mechanisms then reduce the flame vulnerability to the onset of oscillations due to modified KelvinHelmholtz type instabilities. The findings may be relevant for designing strategies to control the stability of oxyfuel combustion.
\end{abstract}

Keywords:

Non-premixed flames, instability, soot, magnetic field, additives

\footnotetext{
${ }^{*}$ Corresponding author: Jocher)

Email address: ajocher@itv.rwth-aachen.de (Agnes 


\section{Introduction}

In combustion processes, instabilities can be desired or deleterious. The prediction and the subsequent control of stability limits may help to reduce damage and mechanical failure of technical combustion systems, as well as enhance mixing and burning rates to obtain complete combustion [1]. Main products of complete combustion are water vapor and carbon dioxide. The latter is known to be a major contributor to climate change and global warming [2]. To reduce anthropogenic carbon dioxide release into the atmosphere, technologies such as oxyfuel combustion are designed to allow for $\mathrm{CO}_{2}$ capture and storage [3]. In oxyfuel combustion, oxygen combined with recycled combustion products are injected into the oxidizer flow. The result is a high $\mathrm{CO}_{2}$ concentration in the exhaust gas stream, which facilitates $\mathrm{CO}_{2}$ separation and therefore capture. However, substituting $\mathrm{N}_{2}$ with $\mathrm{CO}_{2}$ in the oxidizer is found to reduce flame stability (oscillation, lifting limit, attachment-height) [4-6] and to considerably affect sooting tendencies [7-11].

Flame stability on a fundamental level has been extensively investigated with oscillating, non-premixed coflow flames [12-14]. This configuration is especially relevant as these basic flames exhibit features similar to those that characterize locally turbulent reacting flows. Buckmaster and Peters [12] identified, with the help of a linear stability analysis, a modified Kelvin-Helmholtz type $(\mathrm{KH})$ buoyancy-driven instability as the origin of these oscillations. A buoyancy induced shear layer, surrounding the flame sheet, is made responsible for the onset of large-scale outer toroidal vortices. These interact with the flame sheet due to stretch and compression in both radial and axial directions. It was found that the low frequency $(\approx 12 \mathrm{~Hz}$ ) flame oscillations induced by these vortices depend only weakly on fuel type, nozzle size, and fuel jet exit velocity [12]. Cetegen and Dong [6] studied the oscillatory behavior of propane flames burning in $\mathrm{He}-\mathrm{O}_{2}$ and $\mathrm{CO}_{2}-\mathrm{O}_{2}$ atmospheres. The mixtures were selected to considerably change the defined global buoyancy force per unit volume $\left(\rho_{\infty}-\rho_{f}\right) g$, with $\rho_{\infty}$ being the ambient density, $\rho_{f}$ the flame zone density, and $g$ the gravitational acceleration acting along the flame. The authors argued, based on hardly any luminosity change observed compared to flames burning in air, that soot radiation characteristics are not altered significantly. Therefore, Cetegen and Dong [6] suggested that flame oscillations in $\mathrm{He}-\mathrm{O}_{2}$ atmosphere are suppressed due to the reduction of the global buoyancy force, while for $\mathrm{CO}_{2}$ addition, the global buoyancy force is strengthened due to the increase in the ambient density and flame oscillations are triggered. Numerical simulations $[13,14]$ demonstrated that reduced gravity and altered thermal expansion due to combustion processes can suppress the large-scale flame oscillations. Sohn et al. [15] investigated diffusion flame oscillations triggered by radiative heat loss and hinted that in sooty flames heat transfer can be enhanced by radiation to a level high enough to initiate oscillatory combustion. Katta et al. [16] found that the magnitude of KH oscillations in a methane flame decreases with the amount of soot produced when gradually adding acetylene to the fuel stream. Soot formation can also be altered by substituting $\mathrm{N}_{2}$ with $\mathrm{CO}_{2}$ in the oxidizer. Three fundamental mechanisms for soot suppression by $\mathrm{CO}_{2}$ have been identified [7, 9]. First, soot production is reduced due to dilution of the reactive species. Second, thermal effects are induced as a result of discrepancies in different physical properties like the specific heat, the thermal conductivity, and the absorption coefficient for radiation. Third, direct chemical effects are caused by the participation of $\mathrm{CO}_{2}$ in chemical reactions. Identification of the dominant mechanism has been found difficult [9] as all of these interact simultaneously with one another. Recently, Jocher et al. [17, 18] showed that an upward gradient of the square of the magnetic flux density $\nabla\left(\mathbf{B}^{2}\right)$ can also influence soot production in a steady laminar coflow flame. Due to the relatively high paramagnetic susceptibility of oxygen and the inverse temperature dependence of the magnetic field force [19], increasing the magnitude of an upward $\nabla\left(\mathbf{B}^{2}\right)$ leads to enhanced soot production within the flame. This effect is magnified when the $\mathrm{O}_{2}$ content in the coflow is increased. Further investigations showed that naturally oscillating sooting flames, burning in a $\mathrm{CO}_{2}-\mathrm{O}_{2}$ mixture, can be stabilized when exposed to a magnetic field gradient [20]. Local stability analysis near the fuel tube inlet supported the identification of coupling between thermochemical properties and momentum in the sooting oscillating flame as a key mechanism for stabilization. Thus, controlling the onset of this transition could provide further insights in the design of oxyfuel technologies. Here, we show that buoyancy-induced oscillations can be suppressed by substituting $\mathrm{CO}_{2}$ in the oxidizer with $\mathrm{N}_{2}$ in a range of coflow mixtures and applying a magnetic field force opposing gravity. Furthermore, we assess the impact of both strategies on soot formation and the role of the associated radiative heat loss on soot temperature and flame stability. 


\section{Experimental configuration}

Non-premixed ethylene flames are established over an axisymmetric vertical coflow burner first described by Santoro et al. [21]. Ethylene and the oxidizer mixture are injected through two concentric brass tubes with an effective inner diameter of $11 \mathrm{~mm}$ and $102 \mathrm{~mm}$, respectively. This burner configuration has delivered literature on the sooting behavior of a wide range of fuels [10, 11, 22, 23]. Three Bronkhorst EL-FLOW mass flow controllers enable the variation of the oxidizer's $\mathrm{O}_{2}, \mathrm{~N}_{2}$, and $\mathrm{CO}_{2}$ molar contents. The oxidizer coflow is straightened through glass beads, followed by a $50 \mathrm{~mm}$ high ceramic honeycomb with $1.2 \mathrm{~mm}$ cell-size. The $\mathrm{C}_{2} \mathrm{H}_{4}$ flow rate is adjusted by another mass flow controller. In the following, the origin of the coordinates is located at the intersection of the vertical axis of symmetry of the burner and the horizontal fuel tube outlet section. The height above the burner (HAB), i.e. the vertical distance from the origin, is referred to as $z$. The radial distance from the burner's vertical axis of symmetry is $r$. To expose the flames to a fairly uniform upward $\nabla\left(\mathbf{B}^{2}\right)$, the fuel tube outlet is located $130 \mathrm{~mm}$ below the horizontal axis of symmetry of the electromagnet's coils. None of the rig components is magnetic to avoid mechanical interferences. The electromagnetic setup is described in detail in Jocher et al. [17]. The magnitude of $\nabla\left(\mathbf{B}^{2}\right)$ depends on the current flowing through the coils of the electromagnet. With the current setup, the maximum DC current is $60 \mathrm{~A}$ generating a magnetic field of $1 \mathrm{~T}$ at the heart of the electromagnet together with a maximum $\nabla\left(\mathbf{B}^{2}\right)$ of $18.2 \mathrm{~T}^{2} / \mathrm{m}$ downstream of the fuel tube outlet. At this location, the horizontal component of $\nabla\left(\mathbf{B}^{2}\right)$ is negligible as compared to the vertical one, which was evidenced by two-dimensional numerical simulations of the magnetic field calibrated by a set of measurements carried out with a Hall effect sensor [24].

The stabilization process of the flames is first documented with a Phantom v711 camera and a widescreen CMOS sensor. For a $50 \mathrm{~s}$ long sequence of 12-bit monochrome frames recorded at a frame rate of 188 frames per second, each flame is captured on a $800 \mathrm{x}$ 304 pixels $^{2}$ matrix. The exposure time was kept constant at $5.3 \mathrm{~ms}$. The high speed camera was focused on the plane containing the burner axis of symmetry, using a SIGMA $105 \mathrm{~mm}$ F2.8 Macro lens. With this optical arrangement, each pixel in the CMOS array focused light from a volume corresponding to $0.13 \mathrm{~mm}$ in height, $0.13 \mathrm{~mm}$ in width and $1 \mathrm{~mm}$ in depth. Within the range of conditions investigated, the dynamic range of the camera was fully used while the saturation was not reached. To track soot along the stabilization process, the Modulated Absorption/Emission (MAE) technique developed in its two-dimensional formulation is implemented [25]. This technique provides simultaneously two-dimensional fields of soot temperature and volume fraction in axisymmetric laminar non-premixed flames with uncertainty levels lower than $\pm 50 \mathrm{~K}$ and $\pm 0.5 \mathrm{ppm}$, respectively $[26,27]$. Within the red and near infrared spectral ranges (centered at $\lambda_{1}=645 \mathrm{~nm}$ and $\lambda_{2}=785 \mathrm{~nm}(-5 /+7 \mathrm{~nm})$, respectively), the flame is considered an emitting, absorbing, but non-scattering medium. For the laminar coflow flames studied, the flame radiative spectrum in the visible is governed by the continuum radiation from soot. This is particularly true in the upper part of the visible spectrum. In addition, absorption by soot particles produced in these flames is shown to be at least one order of magnitude higher than scattering at large wavelengths in the visible spectrum [28]. In such a configuration, the Radiative Transfer Equation that models the transfer of the radiative intensity can be integrated along the optical pathways followed by the collimated laser beams inside the flame. When the laser beam is blocked, the energy accumulated on a pixel of a camera during the exposure time is mainly attributed to the steady impinging flux emitted by the flame, which can then be imaged within a spectral range located around a wavelength $\lambda$ provided that the camera is mounted with a narrow band filter. When the laser is not blocked, the energy accumulated on the same pixel is complemented by the energy deposited by the non-coherent collimated laser beam. Imaging consecutively the flame with and without the laser beam allows the difference between both frames to be only connected to the spectral absorption coefficient field $\kappa_{\lambda}$. Here, the frames captured by the cameras at a rate of 94 frames per second are recorded by a frame grabber. The exposure time is set to $4.5 \mathrm{~ms}$ for an oxygen molar content in the coflow $\mathrm{X}_{\mathrm{O}_{2}, \mathrm{c}}$ of $60 \%$ and higher, $5.5 \mathrm{~ms}$ for $\mathrm{X}_{\mathrm{O}_{2}, \mathrm{c}}$ between 30 and $55 \%$ and $6 \mathrm{~ms}$ for $\mathrm{X}_{\mathrm{O}_{2}, \mathrm{c}}$ of $25 \%$ as the level of intensity emitted by the flame is especially governed by the coflow oxygen content. Being information integrated over the line-of-sight, the measurements need to be combined with a subsequent deconvolution procedure to compute the local fields $\kappa_{\lambda}(r, z)$. An onionpeeling method [29] combined with a Tikhonov regularization [30] is employed. The soot volume fraction field $f_{v}(r, z)$ can then be inferred using the Mie theory assuming that soot particles are in the Rayleigh limit [4]. The frame captured in the absence of the laser beam is then processed in a similar way to provide the local spectral emission rate $\kappa_{\lambda} B_{\lambda}(r, z)$, where $B_{\lambda}$ is the spectral blackbody radiative intensity at the local temperature $T$ given 
Table 1: Reference conditions and associated specific properties, along the flames' stabilization process, as $\mathrm{CO}_{2}$ is gradually substituted by $\mathrm{N}_{2}$ in the oxidizer stream

\begin{tabular}{lccccccccccc} 
Flame & $\dot{\mathrm{V}}_{\mathrm{C}_{2} \mathrm{H}_{4}}(\mathrm{l} / \mathrm{min})$ & $\dot{\mathrm{V}}_{\mathrm{O}_{2}, \mathrm{c}}(\mathrm{l} / \mathrm{min})$ & $\dot{\mathrm{V}}_{\mathrm{N}_{2}, \mathrm{c}}(\mathrm{l} / \mathrm{min})$ & $\dot{\mathrm{V}}_{\mathrm{CO}_{2}, \mathrm{c}}(\mathrm{l} / \mathrm{min})$ & $\mathrm{X}_{\mathrm{O}_{2}, \mathrm{c}}$ & $\mathrm{X}_{\mathrm{N}_{2}, \mathrm{c}}$ & $\mathrm{X}_{\mathrm{CO}_{2}, \mathrm{c}}$ & $\mathrm{Z}_{\mathrm{st}}$ & $\mathrm{T}_{\text {ad }}(\mathrm{K})$ & $\mathrm{I}_{\text {trans }}(\mathrm{A})$ & $\nabla\left(\mathbf{B}^{2}\right)\left(\mathrm{T}^{2} / \mathrm{m}\right)$ \\
\hline $\mathrm{A}$ & 0.36 & 41 & 0 & 33 & $55 \%$ & $0 \%$ & $45 \%$ & 0.121 & 2255 & 27 & 7.6 \\
$\mathrm{~B}$ & 0.36 & 41 & 3 & 30 & $55 \%$ & $4 \%$ & $41 \%$ & 0.123 & 2265 & 24 & 6.1 \\
$\mathrm{C}$ & 0.36 & 41 & 9 & 24 & $55 \%$ & $12 \%$ & $33 \%$ & 0.127 & 2286 & 18 & 3.6 \\
\hline
\end{tabular}

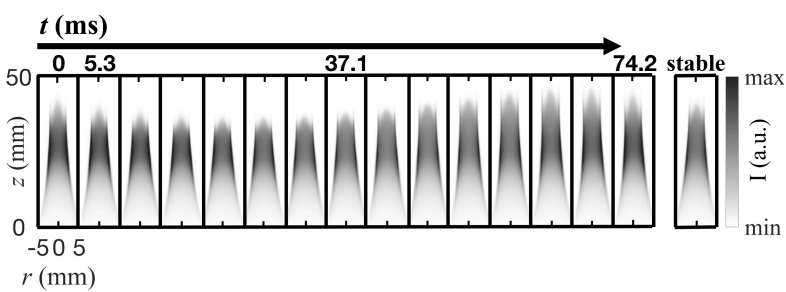

Figure 1: Instantaneous frames of the visible flame captured by a high speed camera. The sequence on the left shows the evolution along a cycle $(12.6 \mathrm{~Hz})$ of the flickering flame in the absence of the magnetic field. When a current of 31 A flows through the coils of the electromagnet, for the same fluid-dynamic boundary conditions, a stable flame is established. Flame A conditions are displayed, Tab. 1.

by Planck's law [31]. As a result, $B_{\lambda}(r, z)$ can be extracted as the ratio $\kappa_{\lambda} B_{\lambda} / \kappa_{\lambda}$. Conducting these measurements within two spectral ranges centred at $\lambda_{1}$ and $\lambda_{2}$ then allows the field of $B_{\lambda_{2}} / B_{\lambda_{1}}$ to be computed. The field of soot temperature $T(r, z)$ can finally be inferred from a lookup table that provides $T$ as a function of the ratio $B_{\lambda_{2}} / B_{\lambda_{1}}$. The procedure driving the interpretation of the soot spectral emission rate field intrinsically includes soot self-absorption along the line-of-sight. In addition, the determination of the soot temperature by the MAE technique does not require any model for the spectral dependence of the soot refractive index as the fields of $\kappa_{\lambda}$ are measured within both spectral ranges of detection. For every wavelength, $B_{\lambda}$ monotonically increases with $T$. As a result, for a given amount of soot, i.e. at a given level of $\kappa_{\lambda}$, an increase in $\kappa_{\lambda} B_{\lambda}$ evidences an increase of the local emission rate emitted by soot over the full spectrum of radiative transfer.

\section{Results and discussion}

\subsection{Initial observations}

On the left of Fig. 1, a sequence of frames displays an oscillation cycle of a $\mathrm{C}_{2} \mathrm{H}_{4}$ diffusion flame, first investigated by Kashif et al. [4], corresponding to the conditions of flame A in Tab. 1. The buoyancy-induced oscillation appears spontaneously in the absence of a magnetic field. When the oscillating flame is exposed to a minimum $\nabla\left(\mathbf{B}^{2}\right)$ of $7.6 \mathrm{~T}^{2} / \mathrm{m}$, corresponding to $27 \mathrm{~A}$ through the coils of the electromagnet, it becomes stable, Fig. 1. When the current through the coils of the electromagnet is reduced after the flame stabilization, a spontaneous flame oscillation can be suddenly observed again. When the coflow $\mathrm{CO}_{2}$ content is fully substituted by $\mathrm{N}_{2}$, a stable flame is established without applying a magnetic field [4]. It is concluded that the stability domain of the $\mathrm{C}_{2} \mathrm{H}_{4}$ flame is a function of the oxidizer's $\mathrm{N}_{2}$ content and the magnitude of $\nabla\left(\mathbf{B}^{2}\right)$. To further assess the stabilizing potential of both parameters, the following conditions are investigated: the $\mathrm{C}_{2} \mathrm{H}_{4}$ and oxidizer flow rates are kept constant at $0.36 \mathrm{l} / \mathrm{min}$ and $74 \mathrm{l} / \mathrm{min}$, respectively, while the oxidizer's $\mathrm{O}_{2}, \mathrm{CO}_{2}$, and $\mathrm{N}_{2}$ contents in volume are varied. The dots shown in Fig. 2 indicate the conditions investigated. Under these conditions, hot wire measurements evidenced a flat velocity profile for the steady laminar oxidizer flow and a fully developed steady laminar fuel flow at the height of the burner tip. The flames that exhibit spontaneous flickering without magnetic field fall within the Strouhal to Richardson number scaling law $S t=0.8 R i^{0.38}$ [32], which ensures that all observed flame oscillations are buoyancy induced.

To assess the importance of radiation in the current study, the radiation-convection parameters $\mathrm{p}_{r c}$ defined by Bhattacharjee and Grosshandler [33] as

$$
\mathrm{p}_{r c}=\frac{\left[\sigma \cdot a \cdot L\left(T_{a d}^{4}-T_{\infty}^{4}\right)\right]}{\left[\rho_{0} \cdot u_{0} \cdot c_{p}\left(T_{a d}-T_{\infty}\right)\right]},
$$

are calculated using the Stefan-Boltzmann constant $\sigma$, the average Planck mean absorption coefficient $a$ based on the average soot volume fraction and $\mathrm{CO}_{2}$ molar fraction for each flame, the average flame length $L$, the adiabatic flame and ambient temperature $T_{a d}$ and $T_{\infty}$, the ethylene density $\rho_{0}$, inflow velocity $u_{0}$, and heat capacity at constant pressure $c_{p}$. It is suggested that radiation is a dominant mechanism for heat transfer in the flame, when $\mathrm{p}_{r c}$ is larger than unity [34]. In the current study, all $\mathrm{p}_{r c}$ values range between 30 and 225 . Therefore, it is concluded that radiation plays an important role for the investigated flames.

To assess the mechanisms leading to flame stabilization or conversely buoyancy induced flame oscillation, three flames referred to as A, B, and C are specified in Tab. 1 and located in Fig. 2. From flame A to $\mathrm{C}, \mathrm{CO}_{2}$ is gradually substituted by $\mathrm{N}_{2}$ while keeping the other parameters constant. All three flames exhibit spontaneous flick- 


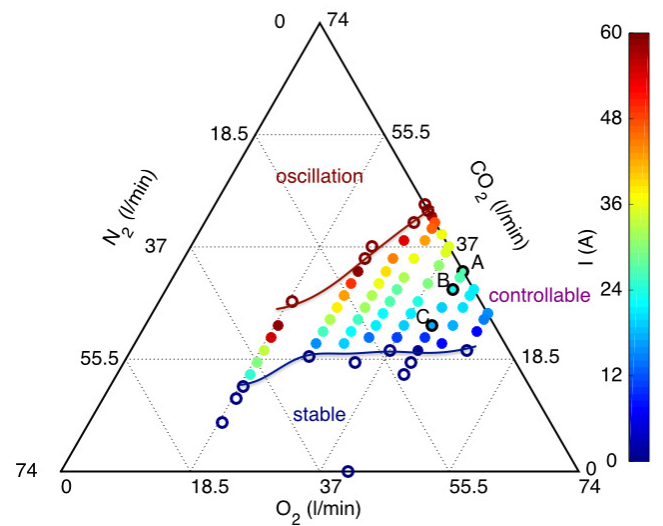

Figure 2: Ternary plot representing the composition of the oxidizer stream. The dots indicate the conditions at which the $\mathrm{C}_{2} \mathrm{H}_{4}$ flames are established. Regions of stable, oscillating, and controllable flames are identified. Below the schematic blue line, flames are naturally stable, while beyond this line they experience spontaneous flickering. Above the schematic red line, the spontaneous flickering could not be suppressed at the available $\nabla\left(\mathbf{B}^{2}\right)$ limit, corresponding to $60 \mathrm{~A}$. In between both lines, spontaneous flickering can be suppressed by the magnetic effect. The current I through the coils of the electromagnet required for the suppression is given by the color of the dots. Empty dots indicate flames that are initially stable or could not be stabilized within the available current range.

ering which can be suppressed by the magnetic effect. The further the conditions are located away from the natural stable domain, i.e. from the blue line in Fig. 2, the higher $\mathrm{I}_{\text {trans }}$ is. Tracking a stabilization mechanism in an oscillating flame is difficult, especially due to the transient regime that the flame exhibits. The interpretation of fields fluctuating with time can then be misleading. Consequently, the pathways leading from stable to oscillating conditions are investigated in the following. The effects of both additives and magnetic gradient on the soot production are first characterized in steady flames and then their influence on the conditions governing the transition from the stable to the oscillating flames are discussed. A current I of 31 A enables the stabilization of the three flames specified in Tab. 1. This magnetic condition will be the starting point for each pathway studied.

\subsection{Combined effects of additives and magnetic gradi- ent on soot production}

First, the impact of varying coflow composition on soot production and spectral emission rate in the steady laminar coflow flames experiencing an identical distribution of $\nabla\left(\mathbf{B}^{2}\right)$ equal to $9.6 \mathrm{~T}^{2} / \mathrm{m}$, corresponding to $31 \mathrm{~A}$, is assessed. Figure 3 shows the spectral absorption coefficient $\kappa_{\lambda}^{\text {int }}$ and spectral emission rate $\left(\kappa_{\lambda} B_{\lambda}\right)^{i n t}$ integrated

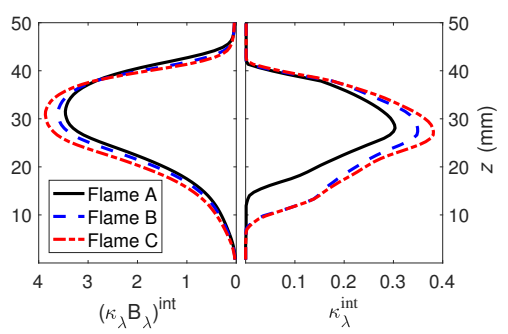

Figure 3: Spectral emission rate (left) and spectral absorption coefficient (right) integrated along the laser beam's line-of-sight as a function of the height above the burner $z$ for different coflow $\mathrm{CO}_{2}$ contents. The current I (31 A) is kept constant.

along the line-of-sight crossing the flame's axis $(r=0)$ evaluated as

$$
\begin{gathered}
\kappa_{\lambda}^{i n t}(z)=\int_{-R_{f l}}^{R_{f l}} \kappa_{\lambda}(r, z) d r \\
\left(\kappa_{\lambda} B_{\lambda}\right)^{i n t}(z)=\int_{-R_{f l}}^{R_{f l}} \kappa_{\lambda}(r, z) B_{\lambda}(r, z) d r .
\end{gathered}
$$

$R_{f l}$ is the radial distance from the flame's axis where both distributions of $\kappa_{\lambda}$ and $\kappa_{\lambda} B_{\lambda}$ have vanished. Thus, $\kappa_{\lambda}^{i n t}$ and $\left(\kappa_{\lambda} B_{\lambda}\right)^{i n t}$ appear as the non-dimensional overall spectral absorption coefficient and the overall spectral emission rate given in $\mathrm{W} / \mathrm{m}^{3}$ along the vertical flame axis. The $\kappa_{\lambda}^{\text {int }}$ profiles follow the soot volume fraction trends in the absence of a magnetic field documented in the literature $[8,35]$ : with decreasing $\mathrm{N}_{2}$ content in the oxidizer (flame $\mathrm{C}$ to $\mathrm{A}$ ), soot inception is delayed and the peak soot volume fraction along the centerline decreases. Here, also in agreement with the literature [8], $\mathrm{N}_{2}$ substitution hardly influences soot oxidation in the upper part of the flame $(z \geq 37 \mathrm{~mm})$ where the $\kappa_{\lambda}^{\text {int }}$ profiles merge into one. Angrill et al. [8] try to explain this observation by increased soot oxidation rates due to the enhanced $\mathrm{OH}$ formation through the chemical reaction $\mathrm{CO}_{2}+\mathrm{H} \rightarrow \mathrm{CO}+\mathrm{OH}$ that are balancing the reduced soot oxidation rates due to the lower adiabatic temperature resulting from the higher $\mathrm{CO}_{2}$ content in the coflow. However, Du et al. [7] found that $\mathrm{CO}_{2}$ addition mainly changes soot formation via the chemical pathway when the flame temperature is kept constant, but that the thermal pathway is dominant with changing flame temperature. Even though the adiabatic flame temperatures are close to each other $(30 \mathrm{~K})$ for flame A to $\mathrm{C}$, what would suggest the chemical pathway to be dominant, given the importance of heat loss through radiation in these flames [33] together with the $\left(\kappa_{\lambda} B_{\lambda}\right)^{\text {int }}$ profiles in Fig. 3, it is suggested that the collapse of the spectral absorption coefficient in the soot oxidation zone is more 


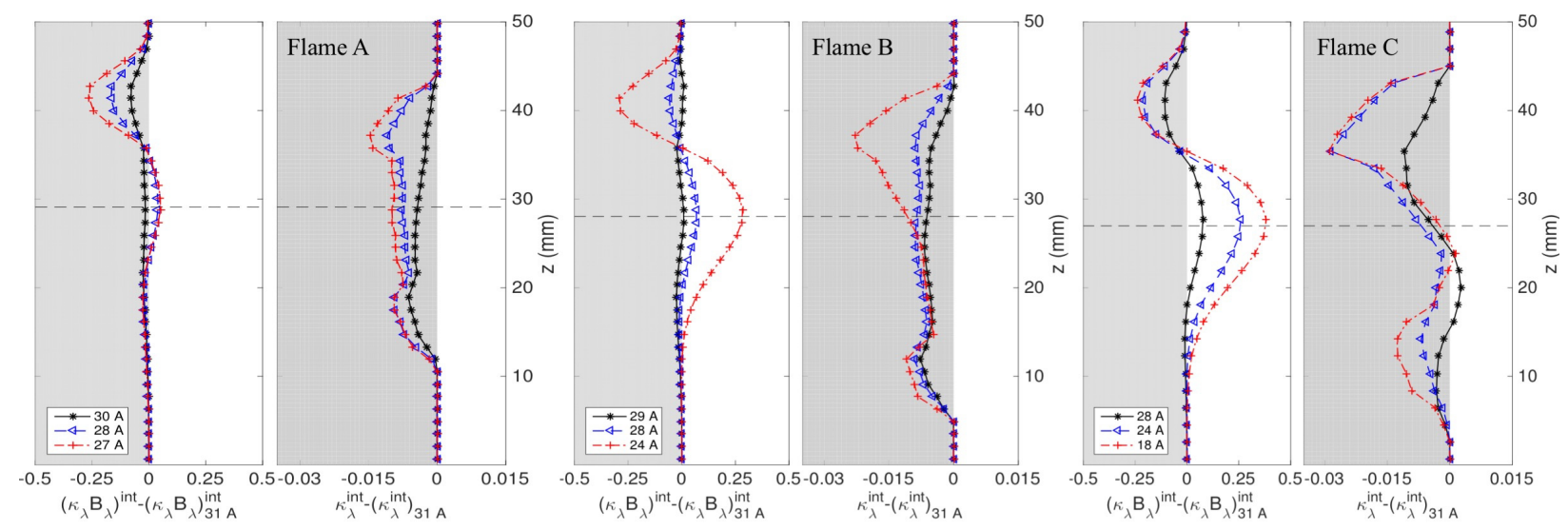

Figure 4: Evolution of the spectral emission rate profiles (left) and spectral absorption coefficient profiles (right). The profiles are integrated along the line-of-sight crossing the flame's axis and the current I is decreased starting from 31 A. For each decrease in the current I, the differences to the profiles at $31 \mathrm{~A}$ are shown for flames A to C. For each flame, the dashed line indicates the location of the peak spectral absorption coefficient for I $=31 \mathrm{~A}$ (Fig. 3). The lowest current applied is set just above $\mathrm{I}_{\text {trans }}$ (Tab. 1) preserving flame stability.

likely to be explained by the thermal pathway. Flame $\mathrm{C}$ has the highest adiabatic flame temperature, Tab. 1. In addition, it is recalled that the spectral emission rate is a function of soot content and temperature and that for every wavelength $B_{\lambda}$ monotonically increases with the soot temperature. Consequently, for $z<37 \mathrm{~mm}$, flame $\mathrm{C}$ exhibits the highest spectral emission rate. For $z \geq 37 \mathrm{~mm}$, the $\left(\kappa_{\lambda} B_{\lambda}\right)^{i n t}$ profiles intersect. This could be explained by an enhanced radiative heat transfer for flame C compared to flame A below this intersection point, leading to a reduction in the flame temperature (flame C) higher up in the flame, while the $\kappa_{\lambda}^{\text {int }}$ profiles collapse. It might be concluded that in this region flame A exhibits the highest flame temperature and therefore enhanced soot oxidation rates.

The findings discussed above are now used to study the influence of a stepwise reduction of the $\nabla\left(\mathbf{B}^{2}\right)$ magnitude. Three levels of current are selected for each flame along the pathway leading to flame flickering. With the current lower bound being slightly higher than $\mathrm{I}_{\text {trans }}$, all flames probed remain stable. As the range of current preserving the flame stability is enlarged when the $\mathrm{N}_{2}$ coflow content is increased, the amplitude of the evolutions shown in Fig. 4 is magnified from flame A to C. However, scaling these evolutions with the magnitude of $\nabla\left(\mathbf{B}^{2}\right)$ is beyond the scope of the present study. All the flames investigated show a similar set of profiles. With decreasing magnitude of $\nabla\left(\mathbf{B}^{2}\right), \kappa_{\lambda}^{i n t}$, i.e. soot production, decreases globally at every HAB. Locally, the sensitivity to this effect is higher in the upper region of the flame $(z \geq 30 \mathrm{~mm})$. A region of still significant soot production evolution is located in the lower part of the flame, where the $\nabla\left(\mathbf{B}^{2}\right)$ decrease leads to a shorter residence time and therefore a downstream shift of the soot inception region. Due to the relatively high mass fraction and paramagnetic susceptibility of oxygen, the main influence of the magnetic field on the non-premixed flame is expected to be caused by the $\mathrm{O}_{2}$ concentration field [17]. Here, the flame is submitted to an upward $\nabla\left(\mathbf{B}^{2}\right)$. As explained by Yamaguchi and Tanimoto [36], the resulting thermo-magneto convection is therefore opposed to buoyancy. For relatively long flames, buoyancy plays an important role. However, with increasing magnitude of $\nabla\left(\mathbf{B}^{2}\right)$, the thermomagneto convection is enhanced [18]. Consequently, the global residence time inside the flame is increased with increasing magnitude of $\nabla\left(\mathbf{B}^{2}\right)$. Furthermore, the thermo-magneto convection will also reduce the velocity deceleration of the fresh oxidizer flow by gravity. The shear stress between the oxidizer and fuel flow will be weakened. Both effects then promote soot formation under magnetic field influence [20]. The increased soot production in the lower part of the flames, not being accompanied by a significant alteration of the $\left(\kappa_{\lambda} B_{\lambda}\right)^{i n t}$ profiles indicates that the local flame temperatures for $\mathrm{I}_{\text {trans }}$ conditions should be higher than for 31 A conditions, in turn leading to locally enhanced soot production rates and narrowing $\kappa_{\lambda}^{\text {int }}$ profiles. Consequently, around the peak $\kappa_{\lambda}^{i n t}$ (dashed line in Fig. 4), the $\left(\kappa_{\lambda} B_{\lambda}\right)^{i n t}$ profiles for $\mathrm{I}_{\text {trans }}$ conditions are dominant. Figure 5 shows a local increase in soot temperature with decreasing $\nabla\left(\mathbf{B}^{2}\right)$. Therefore, beyond the peak $\kappa_{\lambda}^{\text {int }}$ in Fig. 4, $I_{\text {trans }}$ conditions might exhibit the highest soot oxidation rates and the intersections of the $\left(\kappa_{\lambda} B_{\lambda}\right)^{\text {int }}$ profiles are presumably dominated by the $\kappa_{\lambda}^{\text {int }}$ profiles. Both single effects presented, i.e. that due to the $\mathrm{N}_{2} / \mathrm{CO}_{2}$ balance 


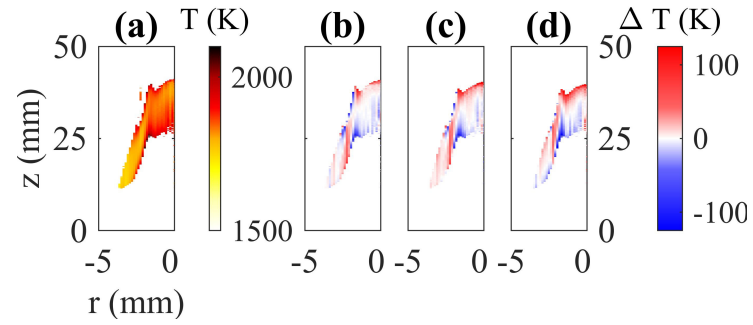

Figure 5: (a) Absolute measured soot temperature for flame $\mathrm{C}$ at $31 \mathrm{~A}$ through the coils of the electromagnet. In (b) to (d) for each decrease in the current I, the field of soot temperature difference to the field at $31 \mathrm{~A}$ is shown for flame $\mathrm{C}$. This is (b) 28-31 A, (c) 24-31 A and (d) 18-31 A.

in the coflow on one hand, and that induced by the exposure to the magnetic gradient on the other hand, follow the trends documented in the literature. Although a combined effect may also contribute to the overall impact on soot production, it does not lead to any reversal of the trends attributed to the aforementioned single effects. As a matter of fact, the following discussions that mainly address both single effects are consistent within the range of conditions investigated.

\subsection{Stabilization pathways with additives and mag- netic field}

Two stabilization mechanisms, the magnetic gradient exposure and the combination of additives in the coflow, that potentially influence each other have been identified in Fig. 2. In Fig. 4, it was discussed that in the central part of the flame above the peak $\kappa_{\lambda}^{i n t}$, the evolution of the $\left(\kappa_{\lambda} B_{\lambda}\right)^{i n t}$ profile is driven by that of the $\kappa_{\lambda}^{i n t}$ profile. Figure 5 presents the difference in temperature distribution as the $\nabla\left(\mathbf{B}^{2}\right)$ magnitude is decreased. Especially the upper part of the flame becomes hotter. Combining the findings, it could be concluded that the temperature increase in the upper flame with decreasing $\nabla\left(\mathbf{B}^{2}\right)$ magnitude is related to a reduction in the overall soot production, Fig. 4.

A mechanistic explanation of the flickering onset can now be adapted from Cetegen and Dong [6] who mentioned that the initial buoyancy in diffusion flames may not be sufficient to initiate flame oscillation and that the flow instability develops farther downstream, where the low flame zone densities result in significantly high buoyant acceleration. In the current study, at the peak $\nabla\left(\mathbf{B}^{2}\right)$, the soot temperature in the upper part of the flame was found to be reduced, resulting in an increased density of the hot combustion gases and therefore a reduced buoyant acceleration compared to the flames with reduced $\nabla\left(\mathbf{B}^{2}\right)$. In turn, an increased buoyant acceleration of hot combustion gases could lead to radial flame narrowing, entrainment of cool oxidizer gases and subsequent vortex generation, corresponding to flame flickering. The control of flame oscillation with enhanced soot formation was also found by Katta et al. [16] when doping an oscillating methane-air flame with acetylene. Furthermore, the thermo-magneto convection reduces the velocity of the fresh oxidizer flow and the shear stress between the oxidizer and fuel flow is weakened leading to a flame that is less prone to modified $\mathrm{KH}$ instabilities under magnetic field exposure. The impossible stabilization of a methane flame at the same fluid mechanic boundary conditions compared to a $\mathrm{C}_{2} \mathrm{H}_{4}$ flame could then be explained by the consideration that the natural flame oscillations are buoyancy-induced, but possibly sustained by radiative heat transfer in the investigated flames. Therefore, the oscillation can be suppressed by an enhanced soot formation and subsequent cooling of the flame. It is further suggested that the mechanism to enhance soot formation can be either the addition of $\mathrm{N}_{2}$ to the ambient mixture, or an increase in the external magnetic field gradient, or a combination of both.

\section{Concluding remarks}

While the impact of the coflow dilution on soot formation has already been studied in the past, this has never been related to flame stability that is highly influenced by soot radiation and flame temperature. The present study unveiled a domain for different oxidizer mixtures composed of $\mathrm{CO}_{2}, \mathrm{~N}_{2}$, and $\mathrm{O}_{2}$ where the stability of an ethylene non-premixed flame can be controlled. In addition, a stabilization phenomenon triggered by a magnetic field is experimentally documented over the aforementioned domain. Flame stabilization through magnetic field exposure was explained through enhanced soot formation and subsequent flame cooling in the flame. Based on our study, magnetic fields, other flame temperature reducing or soot increasing techniques could increase the stability of flame investigations for example at higher pressure levels relevant for practical combustion devices. A systematic shaping of magnetic fields [37, 38] might allow for lower magnetic fields and currents to achieve more local modifications of combustion processes.

\section{Acknowledgments}

The work was financially supported by the Université franco-allemande/Deutsch-Französische Hochschule. The authors feel grateful to M. Kashif, H. Dutilleul, and J.M. Citerne for their technical support. 


\section{References}

[1] M. Matalon, Annu. Rev. Fluid Mech. 39 (2007) 163-191.

[2] P. Friedlingstein, R. M. Andrew, J. Rogelj, G. P. Peters, J. G Canadell, R. Knutti, G. Luderer, M. R. Raupach, M. Schaeffer, D. P. van Vuuren, C. L. Quéré, Nat. Geosci. 7 (2014) 709-715.

[3] IPCC, Cambridge University Press, New York (2005). Special report on carbon dioxide capture and storage.

[4] M. Kashif, J. Bonnety, P. Guibert, C. Morin, G. Legros, Opt. Express 20 (2012) 28742

[5] J. Min, F. Baillot, Combust. Flame 159 (2012) 3502-3517.

[6] B. M. Cetegen, Y. Dong, Exp. Fluids 28 (2000) 546-558.

[7] D. Du, R. Axelbaum, C. Law, Symp. (Int.) Combust. 23 (1991) 1501-1507.

[8] O. Angrill, H. Geitlinger, T. Streibel, R. Suntz, H. Bockhorn, Proc. Combust. Inst. 28 (2000) 2643-2649.

[9] F. Liu, H. Guo, G. J. Smallwood, O. L. Gülder, Combust. Flame 125 (2001) 778-787.

[10] M. Kashif, P. Guibert, J. Bonnety, G. Legros, Combust. Flame 161 (2014) 1575-1586.

[11] M. Kashif, J. Bonnety, A. Matynia, P. D. Costa, G. Legros, Combust. Flame 162 (2015) 1840-1847.

[12] J. Buckmaster, N. Peters, Symp. (Int.) Combust. 21 (1988) 1829-1836.

[13] R. Davis, E. Moore, W. Roquemore, L.-D. Chen, V. Vilimpoc, L. Goss, Combust. Flame 83 (1991) 263-270.

[14] J. Ellzey, E. Oran, Symp. (Int.) Combust. 23 (1991) 1635-1640.

[15] C. Sohn, J. Kim, S. Chung, K. Maruta, Combust. Flame 123 (2000) 95-106.

[16] V. R. Katta, W. M. Roquemore, A. Menon, S.-Y. Lee, R. J. Santoro, T. A. Litzinger, Proc. Combust. Inst. 32 (2009) 1343-1350.

[17] A. Jocher, H. Pitsch, T. Gomez, G. Legros, Proc. Combust. Inst. 35 (2015) 889-895.

[18] A. Jocher, J. Bonnety, H. Pitsch, T. Gomez, G. Legros, Proc. Combust. Inst. 36 (2017) 1377-1385.

[19] E. Yamada, M. Shinoda, H. Yamashita, K. Kitagawa, Combust. Flame 135 (2003) 365-379.

[20] A. Jocher, H. Pitsch, T. Gomez, J. Bonnety, G. Legros, Phys. Rev. E 95 (2017) 063113.

[21] R. Santoro, H. Semerjian, R. Dobbins, Combust. Flame 51 (1983) 203-218.

[22] F. Liu, G. Hongsheng, G. J. Smallwood, O. L. Gülder, Combust. Theor. Model. 7 (2003) 301-315.

[23] C. S. McEnally, L. D. Pfefferle, Environ. Sci. Technol. 45 (2011) 2498-2503.

[24] G. Legros, T. Gomez, M. Fessard, T. Gouache, T. Ader, P. Guibert, P. Sagaut, J. Torero, Proc. Combust. Inst. 33 (2011) 10951103.

[25] G. Legros, Q. Wang, J. Bonnety, M. Kashif, C. Morin, J.-L. Consalvi, F. Liu, Combust. Flame 162 (2015) 2705-2719.

[26] Q. Wang, G. Legros, J. Bonnety, C. Morin, Proceedings of the Combustion Institute 36 (2017) 3227 - 3235.

[27] Q. Wang, G. Legros, J. Bonnety, C. Morin, A. Matynia, J.-L. Consalvi, F. Liu, Combustion and Flame 183 (2017) 242 - 252.

[28] F. Liu, D. Snelling, K. Thomson, G. Smallwood, Appl. Phys. B 96 (2009) 623-636.

[29] K. J. Daun, K. A. Thomson, F. Liu, G. J. Smallwood, Appl. Opt. 45 (2006) 4638

[30] E. O. Åkesson, K. J. Daun, Appl. Opt. 47 (2008) 407-416.

[31] G. Legros, J. Torero, Proc. Combust. Inst. 35 (2015) 2545-2553.

[32] B. M. Cetegen, K. D. Kasper, Phys. Fluids 8 (1996) 2974.

[33] S. Bhattacharjee, W. L. Grosshandler, Combust. Flame 77 (1989) 347-357.

[34] C. Kaplan, C. Shaddix, K. Smyth, Combust. Flame 106 (1996) 392-405.
[35] J. Kent, H. Wagner, Combust. Sci. Technol. 41 (1984) 245-269.

[36] M. Yamaguchi, Y. Tanimoto, Magneto-Science - Magnetic Field Effects on Materials: Fundamentals and Applications, Springer Berlin Heidelberg (Germany), 2006.

[37] J. E. Martin, A. Snezhko, Rep. Prog. Phys. 76 (2013) 126601.

[38] K. J. Solis, J. E. Martin, Soft Matter 10 (2014) 9136-9142. 